\title{
Pulsed Combustion of Hydrocarbon Fuels in a Supersonic Model Combustor
}

\author{
Taichang Zhang ${ }^{1}$, Xuejun Fan ${ }^{2}$, Jing Wang ${ }^{3}$, Jianguo $\mathrm{Li}^{4}$ and Gong $\mathrm{Yu}^{5}$ \\ Institute of Mechanics, Chinese Academy of Sciences, Beijing, 100190, P. R. China
}

\begin{abstract}
Pulsed combustion of hydrocarbon fuels (ethylene and kerosene) in a Mach number 2.5 supersonic model combustor was experimentally investigated using a pulse spark igniter located in the center of a cavity. The results demonstrated that pure pulsed combustion of ethylene could exist at relatively low stagnant temperatures while pulse-induced stable combustion could be obtained at higher temperatures. Experiments also showed that no significant pulsed combustion of kerosene existed when ethylene was used as pilot flame because the combustion of pilot ethylene offers much more heat and radicals than that supplied by discharging of the spark plug.
\end{abstract}

\section{Introduction}

M AINTAINING a stable flame inside a combustor is crucial for a practical scramjet engine over a wide range of Mach numbers. Self-ignition and stable combustion can only occur when the flow and fuel conditions are within the limits of flame stabilization in the combustor. ${ }^{1-3}$ The region for stable combustion of hydrocarbon fuels is limited by relatively long ignition delay time compared to the resident time. The stability limits could be extended by reducing the reaction time through the use of continuous heat addition such as fuels partially cracking, ${ }^{4,5}$ pilot hydrogen, ${ }^{6,7}$ or plasma jet ${ }^{8}$ etc. If continuous heat source is not cost effective, pulsed energy sources, such as a spark igniter, could be alternatively used to temporally establish the chemical reactions with elevated temperature and bursting source of radicals such that the pulsed combustion could be accomplished beyond the stability limits.

This work has two main objectives: 1) to examine the possibilities of hydrocarbon fuels combustion using pulsed ignition sources with flow or fuel conditions beyond the limits of stable combustion; 2) to explore the potential combustion modes of hydrocarbon fuels. Ethylene and supercritical kerosene are selected as the test fuels due to their potential applications in Scramjet propulsion.

\section{Experimental Specifications}

The experiments were conducted in a Mach number 2.5 direct-connect wind tunnel facility, which consists of a vitiated air supply system, a multi-purpose supersonic model combustor, and a fuel delivery and heating system. The vitiated air heater, burning with $\mathrm{H}_{2}, \mathrm{O}_{2}$ and air, is used to supply heated airflow. The air heater is capable of supplying heated air at stagnation temperatures of 800-2100 K and stagnation pressures of 0.6-2.5 MPa. The model combustor is shown in Fig. 1. It has a total length of $1450 \mathrm{~mm}$, consisting of one nearly constant area section of 400 $\mathrm{mm}$ and three divergent sections of 400,300 , and $350 \mathrm{~mm}$ with the expansion angles of 1.3, 2.9, and 4.0 degrees, respectively. The entry cross section of the combustor is $50 \mathrm{~mm}$ in height and $70 \mathrm{~mm}$ in width.

An integrated fuel injector/flameholder cavity module is installed on one side of the combustor in section 1, with a depth of $12 \mathrm{~mm}$, a 45-degree aft ramp angle, and an overall length-to-depth ratio of 7 . Two orifices of $1.5 \mathrm{~mm}$ in diameter are available for the pilot fuel injection. Room temperature pilot fuel is injected normally to the airflow from one side of the combustor just $8 \mathrm{~mm}$ upstream of the edge of the cavity, specifically at the streamwise location of $625 \mathrm{~mm}$. Ethylene or supercritical kerosene is injected from a single orifice of $4.0 \mathrm{~mm}$ diameter located on the

\footnotetext{
${ }^{1}$ Assistant Professor, National Key Laboratory of High Temperature Gas Dynamics.

${ }^{2}$ Professor, National Key Laboratory of High Temperature Gas Dynamics, xfan@imech.ac.cn, 15 Beisihuanxi Road, Beijing, China, Member AIAA.

${ }^{3}$ Assistant Professor, National Key Laboratory of High Temperature Gas Dynamics.

${ }^{4}$ Professor, National Key Laboratory of High Temperature Gas Dynamics.

${ }^{5}$ Professor, National Key Laboratory of High Temperature Gas Dynamics, Member AIAA.
} 
upstream step of the cavity and $48 \mathrm{~mm}$ upstream the orifices for a pilot fuel. Ethylene is ignited without pilot gas while supercritical kerosene is ignited with pilot ethylene.

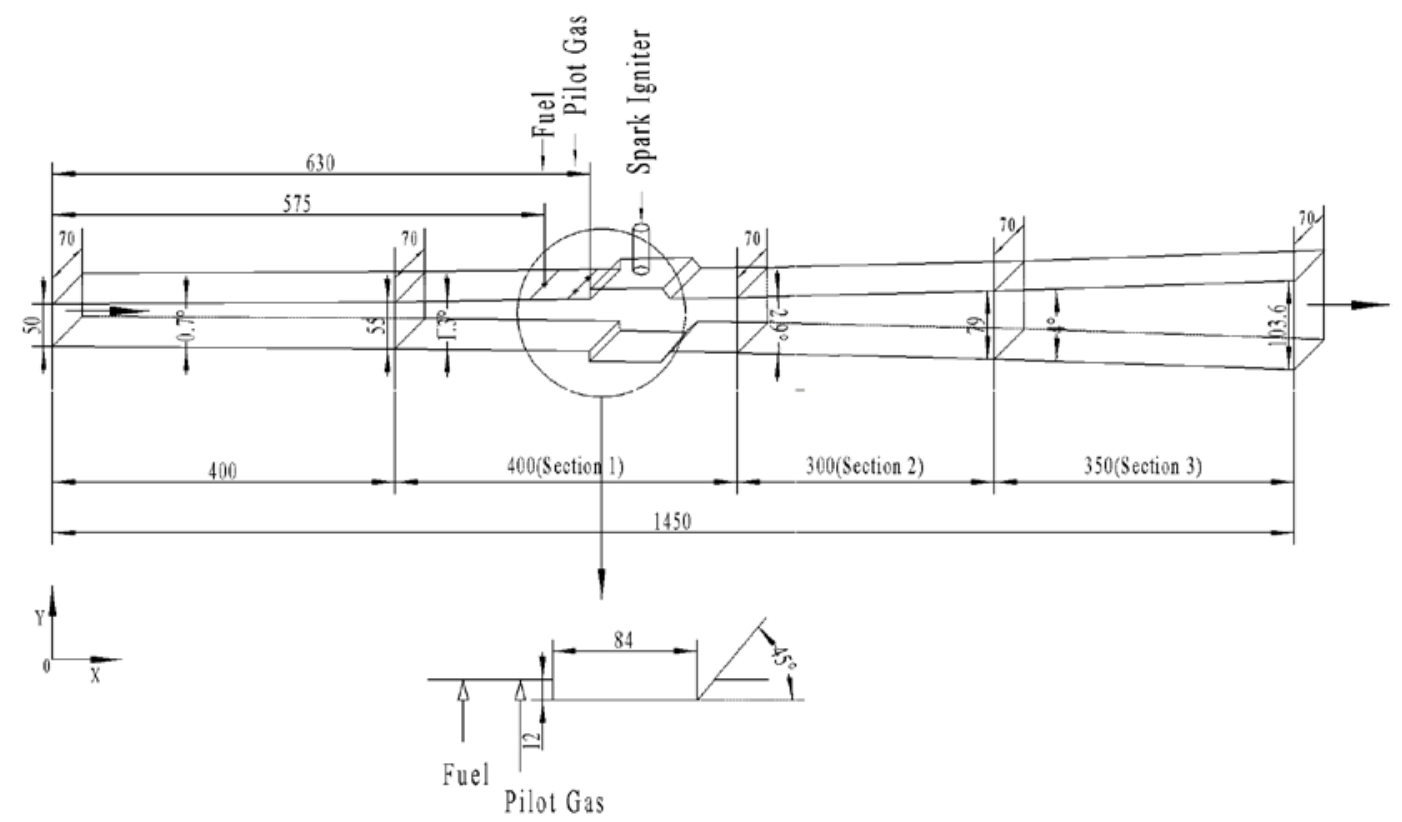

Figure 1. Schematic of the Mach 2.5 model combustor (top) and configurations of two integrated fuel injection/flameholder modules (bottom). All length dimensions are in mm.

Ethylene (purity 99.5\%, Linggas Ltd, Tianjin, China) and China no.3 aviation kerosene were employed herein. A $50 \mathrm{~J} /$ pulse spark plug (Xuzhou Combustion Control Technology Co. LTD, China) installed on the center of the cavity floor was used for ignition with a peak voltage of $2500 \mathrm{~V}$ and a frequency of approximate $5 \mathrm{~Hz}$. Figure 2 shows a picture of plug in discharging.

The stagnation pressure and temperature of the vitiated air were respectively measured using a CYB$10 \mathrm{~S}$ pressure transducer (accuracy $\pm 0.1 \%$, Beijing ZhongHangJiDian Technology Co. Ltd, China) and a Type-B thermocouple. Distribution of the static pressure in the axial direction was determined by Motorola MPX2200 pressure transducers installed along the centerline of the model combustor sidewalls.

Three weight sensors (Shanghai TM, Model No. NS-TH3), equilaterally spaced and connected in series, were used to support the platform and measure the thrust changes during the experiments. This system yielded a maximum force reading of $7500 \mathrm{~N}$ with an uncertainty of $0.2 \%$.

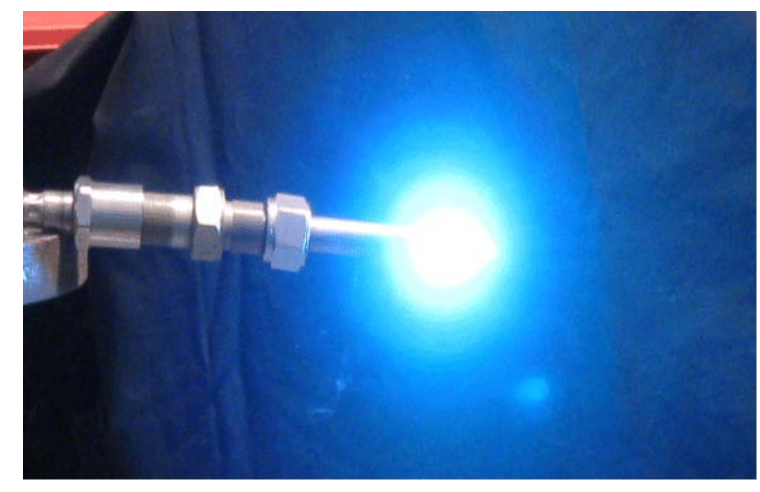

Figure 2. Discharging of the $50 \mathrm{~J} /$ pulse spark plug.

\section{Results and Discussions}

\section{A. Pulsed Combustion of Ethylene}

Pulsed combustion of ethylene was investigated at the airflow conditions of a constant pressure (1.33 MPa) and three different stagnation temperatures (1030, 1070 and $1830 \mathrm{~K})$.

Figure 3 shows the comparison of the static pressure time history at a streamwise location $\mathrm{x}=700 \mathrm{~mm}$ for ethylene combustion at a stagnation temperature of $1030 \mathrm{~K}$ with and without discharging of the spark plug. The ethylene equivalence ratio $\left(\varphi_{\mathrm{C} 2 \mathrm{H} 4}\right)$ is 0.39 . Location $x=700 \mathrm{~mm}$ is place where static pressure peaks. No combustion occurs without the spark discharging, while pulsed combustion occurs at the frequency of discharging $(\sim 5 \mathrm{~Hz})$. 
Figure 4 shows the corresponding time histories of the thrust increments for the two cases. These two figures clearly show that pulsed combustion mode could occur even the flow condition is beyond the limit of stable combustion.

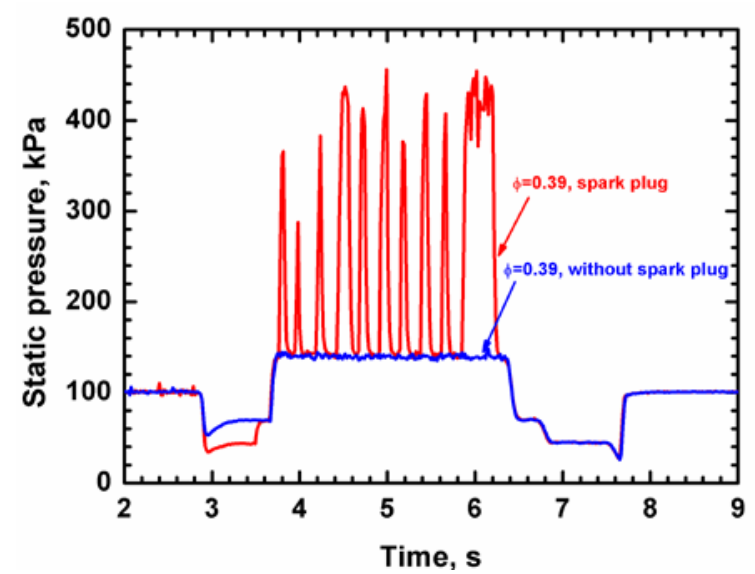

Figure 3. Time histories of static pressure at $\mathrm{x}=$ $700 \mathrm{~mm}$ for the pulsed combustion of ethylene at a vitiated air stagnation temperature of 1030

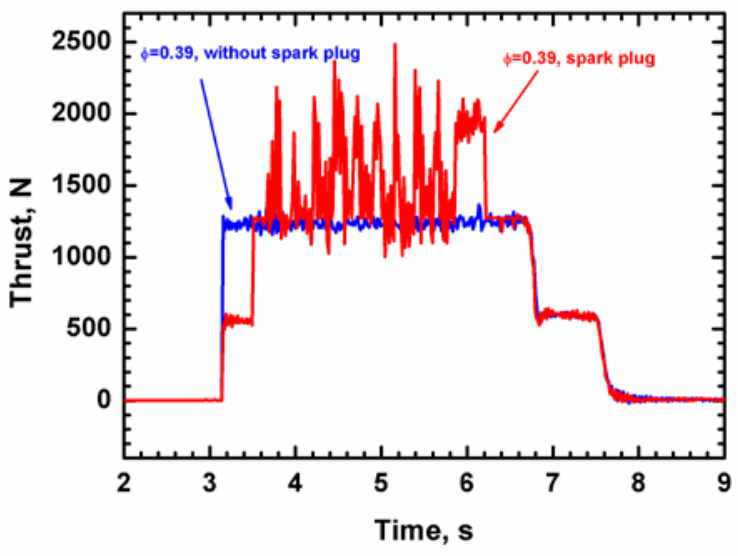

Figure 4. Time histories of thrust for the pulsed combustion of ethylene at a vitiated air stagnation temperature of $1030 \mathrm{~K}$.

Figure 5 shows the time histories of static pressure at $\mathrm{x}=700 \mathrm{~mm}$ for ethylene combustion at a stagnation temperature of $1070 \mathrm{~K}$ with spark discharging at three different ethylene equivalence ratios of $0.27,0.30$ and 0.39 . At $\varphi_{\mathrm{C} 2 \mathrm{H} 4}=0.27$ no combustion occurs. At $\varphi_{\mathrm{C} 2 \mathrm{H} 4}=0.30$ there is no combustion for the first one seconds but a strong pulse appears at the $5^{\text {th }}$ second followed immediately by a stable combustion. At a higher ethylene equivalence ratio of 0.35 , two spikes of pulsed combustion can be observed before stable combustion occurs at the time of 4.2 second.

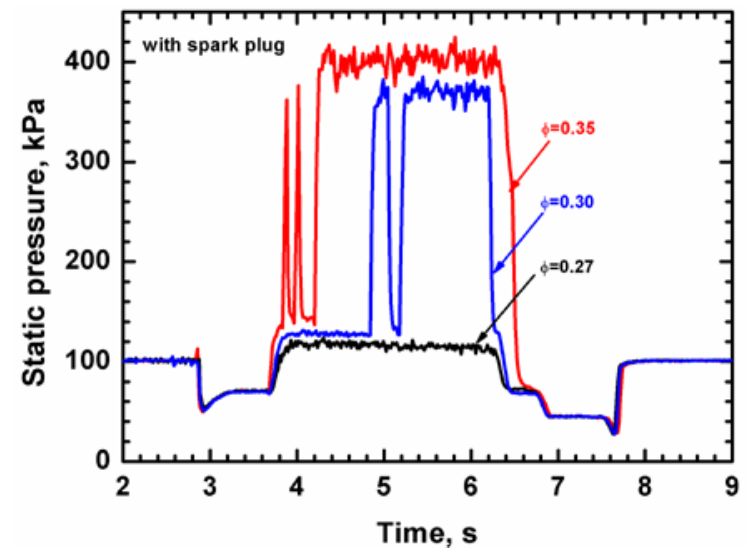

Figure 5. Time histories of static pressure at $\mathrm{x}=$ $700 \mathrm{~mm}$ for the pulsed combustion of ethylene at a vitiated air stagnation temperature of $1070 \mathrm{~K}$.

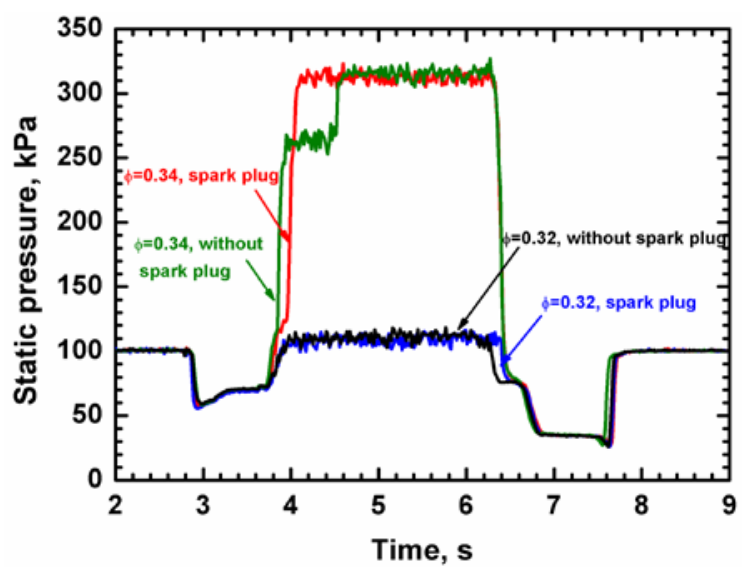

Figure 6. Time histories of static pressure at $\mathrm{x}=$ $700 \mathrm{~mm}$ for the pulsed combustion of ethylene at a vitiated air stagnation temperature of $1830 \mathrm{~K}$.

Figure 6 shows the comparison of the static pressure time history at location $\mathrm{x}=700 \mathrm{~mm}$ for ethylene combustion at a higher stagnation temperature of $1830 \mathrm{~K}$ with and without discharging of the spark plug. No combustion occurs at $\varphi_{\mathrm{C} 2 \mathrm{H} 4}=0.32$ regardless of spark discharging, while at $\varphi_{\mathrm{C} 2 \mathrm{H} 4}=0.34$ stable combustion is quickly established either with or without the spark discharging, even though the highest pressure level with the spark is reached about half seconds earlier than that without spark. In this high temperature case no pulsed combustion is observed.

It is concluded that discharging of spark plug is more effective at relative low temperature. It is also interesting to see that ethylene at $\varphi_{\mathrm{C} 2 \mathrm{H} 4}=0.30$ can be ignited and maintain a stable combustion at stagnant temperature of 1070 K (Fig. 5), but no ignition and combustion occur at $\varphi_{\mathrm{C}_{2} \mathrm{H} 4}=0.32$ and stagnation temperature of $1830 \mathrm{~K}$ (Fig. 6). The possible explanation is the change in the mole fraction of water vapor in the vitiated air. The mole fraction of water vapor at $1830 \mathrm{~K}$ is approximately 0.23 , which is much higher than that of 0.12 at $1070 \mathrm{~K}$. 


\section{B. Pulsed Combustion of Supercritical Kerosene}

As mentioned above, pulsed combustion occurs at low temperature. Thus the combustion experiments of supercritical kerosene were performed at $1150 \mathrm{~K}$. Ethylene is used as pilot fuel due to the difficulty in kerosene ignition.

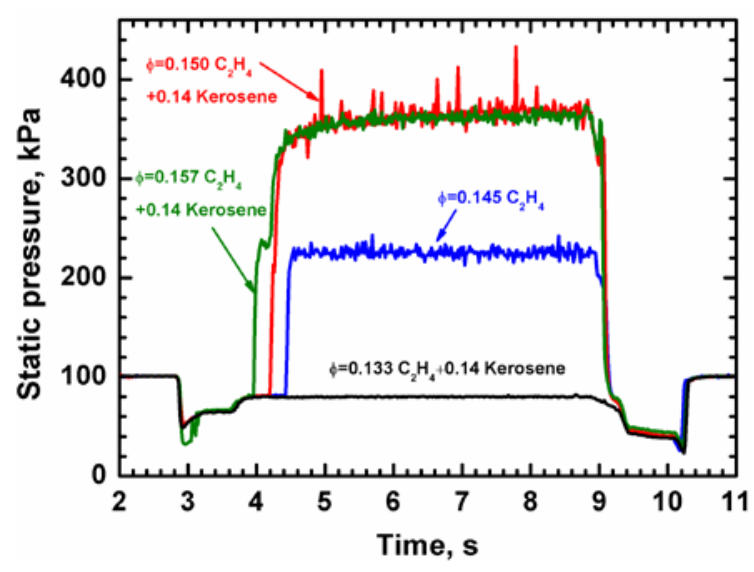

Figure 7. Time histories of static pressure at $x=$ $650 \mathrm{~mm}$ for the pulsed combustion of kerosene with different pilot ethylene concentrations at a stagnation temperature of $1150 \mathrm{~K}$.

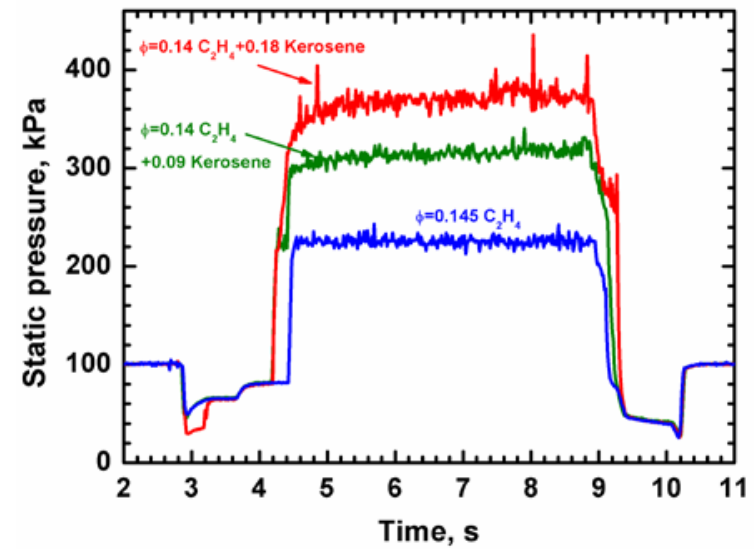

Figure 8. Time histories of static pressure at $\mathrm{x}=$ $650 \mathrm{~mm}$ for the pulsed combustion of kerosene with different kerosene concentrations at a stagnation temperature of $1150 \mathrm{~K}$.

Figure 7 shows the time histories of static pressure at $\mathrm{x}=650 \mathrm{~mm}$ for pulsed combustion of kerosene with different concentrations of pilot ethylene at a stagnation temperature of $1150 \mathrm{~K}$. The equivalence ratio of kerosene ( $\varphi_{\text {kerosene }}$ ) was kept constant at 0.14 . Ethylene and supercritical kerosene were injected at $3.5 \mathrm{~s}$ and $4.0 \mathrm{~s}$, respectively, and both shut down at 8.5s. The spark plug worked from 3.5-8.5s. There is no combustion at $\varphi_{\mathrm{C} 2 \mathrm{H} 4}=0.133$ but some small spikes appeare in an intermittent way at $\varphi_{\mathrm{C} 2 \mathrm{H} 4}=0.150$. There is no any pulse peak at $\varphi_{\mathrm{C} 2 \mathrm{H} 4}=0.157$. The kerosene should be ignited by the combustion of pilot ethylene rather than discharging, otherwise kerosene is ignited by discharging, and the pulse peaks of static pressure should be on the base of $230 \mathrm{kPa}$ rather than that of $360 \mathrm{kPa}$. This is reasonable that heat and radicals supplied by the combustion of pilot ethylene are much higher than that offered by discharging.

Figure 8 shows that the time histories of static pressures at $\mathrm{x}=650 \mathrm{~mm}$ for pulsed combustion of kerosene at different kerosene concentrations and a stagnation temperature of $1150 \mathrm{~K}$. No apparent pulse peak is measured at $\varphi_{\text {kerosene }}=0.09$, while a few slight pulse peaks appear at $\varphi_{\text {kerosene }}=0.18$. Similar to the static pressure in Figure 7 , the pulse peaks of static pressure is on the base of static pressure of the combustion of kerosene and ethylene, rather than on the base of static pressure of ethylene combustion. This indicates that discharging is less effective than the combustion of pilot ethylene in assisting kerosene combustion.

\section{Concluding Remarks}

Pulsed combustion of hydrocarbon fuels (ethylene and kerosene) was experimentally investigated beyond stability limits with the assistance of a pulse spark igniter in a $\mathrm{Ma}=2.5$ supersonic model combustor. The pulsed combustion of ethylene presents two modes: pure pulsed combustion mode at relatively low stagnant temperatures and pulse-induced stable combustion mode at high temperatures. The combustion of supercritical kerosene with spark discharging is different from that of ethylene. Because the heat and radicals supplied by the combustion of pilot ethylene are much higher than that offered by discharging, no strong pulsed combustion of kerosene can be obtained when the combustion of pilot ethylene is stable. The effecs of spark frequency and pulse width on the combustion will be examined in the future.

\section{Acknowledgments}

Current research program at the Chinese Academy of Sciences was supported by the National Natural Science Foundation of China under Contract No. 91016005 and 10621202. The authors thanks Mr. X. S. Wei, Prof. X. N. Lu, and Mr. Y. Li for their technical support. 


\section{References}

${ }^{1}$ Ozawa, R. I., "Survey of Basic Data on Flame Stabilization and Propagation for High Speed Combustion Systems,” U.S. Air Force AFAPL Technical Report TR-70-81, 1970.

${ }^{2}$ Ben-Yakar, A., and Hanson, R. K., "Cavity Flame-Holders for Ignition and Flame Stabilization in Scramjets: An Overview," Journal of Propulsion and Power, Vol. 17, No. 4, 2001, pp. 869-877.

${ }^{3}$ Rasmussen, C. C., and Driscoll, J. F., "Blowout Limits of Flames in High-Speed Airflows: Critical Damkohler Number," AIAA Paper 2008-4571, 44th AIAA/ASME/SAE/ASEE Joint Propulsion Conference \&Exhibit, July 2008, Hartford, CT.

${ }^{4}$ Colket, M. B., and Spadaccini, L. J., “Scramjet Fuels Autoignition Study,” Journal of Propulsion and Power, Vol. 17, No. 2, 2001, pp. 315-323.

${ }^{5}$ Fan, X, Yu, G. Li, J. G., Lu, X. N., Zhang, X. Y., and Sung, C. J., “Combustion and Ignition of Thermally Cracked Kerosene in Supersonic Model Combustors,” Journal of Propulsion and Power, Vol.23, No.2, March-April 2007. pp. $317-324$.

${ }^{6}$ Vinogradov, V., Kobigsky, S., and Petrov, M., "Experimental Investigation of Liquid Carbonhydrogen Fuel Combustion in Channel at Supersonic Velocities,” AIAA Paper 92-3429, July 1992.

${ }^{7}$ Kay, I. W., Peshke, W. T., and Guile, R. N., "Hydrocarbon-Fueled Scramjet Combustor Investigation," Journal of Propulsion and Power, Vol. 8, No. 2, 1992, pp. 507-512.

${ }^{8}$ Kimura, I., Aoki, H., and Kato, M., "The Use of a Plasma Jet for Flame Stabilization and Promotion of Combustion in Supersonic Air Flows,” Combustion and Flame, Vol. 42, 1981, pp. 297-305. 